\title{
REPENSANDO LA LITERATURA COMO ARTE (Ensayo sobre una definición de la literatura)
}

\author{
KURT SPANG \\ Universidad de Navarra
}

\begin{abstract}
Tóda ciencia se replantea una y otra vez sus fundamentos y sus modos de argumentar.
\end{abstract}

R. Alvira

Esos ideales de superobjetividad comparten el mismo error de principio que subyace al (...) llamado prejuicio platónico, la suposición, enteramente incorrecta de que hay una y sólo una solución que es la única y la mejor para toda clase de problemas...

J. L. GONZÁLEZ Quirós

\section{PRELIMINARES}

La primera de las dieciséis acepciones de la voz 'literatura' que recoge M.-Á. Garrido Gallardo ${ }^{1}$ del Diccionario de Escarpit, afirma que la literatura es arte. Como veremos a continuación esta observación es problemática porque hoy por hoy el mero intento de definir el arte ya se convierte en una empresa sumamente comprometedora.

El que presuma que la voz 'arte' corresponde a una realidad coherente y simple con su pertinente definición, el que crea que es posible hallar el más pequeño denominador común del arte en singular tropezará irremediablemente con serias dificultades.

Basta con hojear la Pequeña historia de la teoría del arte de Udo Kultermann ${ }^{2}$ para darse cuenta de las calamidades definitorias que atrave-

\footnotetext{
1 «Arte de la palabra por oposición a las otras artes (la pintura, la música, etc.). Actualmente es su sentido 'fuerte'», Nueva Introducción a la Teoría de la Literatura, Madrid, Síntesis, 2004, 19.

${ }^{2}$ Kultermann, U., Kleine Geschichte der Kunsttheorie. Von der Vorgeschichte bis zur Gegenwart, Darmstadt, Wissenschaftliche Buchgesellschaft, 1998.
}

Rlit, LXVII, 133 (2005), 5-30 
saron y siguen atravesando los teóricos del arte y sus historiadores para acabar llegando, finalmente, a la conclusión lacónica de que arte es todo lo que se declara ser arte.

Nunca será posible una palabra concluyente, una solución definitiva de la cuestión, solamente perspectivas nuevas, acentuaciones modificadas, aspectos de una realidad cambiada que se integran en la tradición ${ }^{3}$.

Este es el balance al que llega el autor después de analizar las teorías del arte «desde la prehistoria hasta el presente» ${ }^{4}$. La única utilidad que concede a las definiciones existentes es su propiedad de «puntos de cristalización que articulan el recorrido del pensamiento a través de las generaciones $»^{5}$. Y, en efecto, el libro se limita a dar testimonio de la proliferación de definiciones del arte a lo largo de los siglos y milenios.

No obstante, la pregunta que me preocupa en este ensayo es la de si, a pesar de esta diversidad y multiplicidad, no pudiera existir la posibilidad de encontrar unos elementos esenciales que se repitan en cada arte, por tanto, también en la literatura, y que formarían, por consiguiente, un conjunto de constantes fundamentales que con realizaciones diversas será posible apreciar en todas las artes y en cada una de sus obras. De no ser así, poco sentido tendría hablar de 'arte' como noción general y eje sustancial y esencial de sus diversas manifestaciones: las artes.

El mencionado libro, y con él un buen número de autores actuales preocupados de una manera o de otra por cuestiones relacionadas con el arte, son hijos del postmodernismo; y como tales parece que experimentan mayor satisfacción en la deconstrucción que conduce el pensamiento contemporáneo inexorablemente hacia caminos pluralistas y que rehúye y sospecha de constantes y univocidades. Se rinde culto a la horizontalidad y con ella a la relatividad que acepta como única posibilidad la cadena infinita de las facticidades entendidas como eslabones que se han convertido en una especie de salvavidas del intelectual moderno, aunque sean sólo simulacros de una conclusión. Se rehúye la reflexión consecuente, las jerarquías y, por consiguiente, resulta cada vez más difícil elaborar un concepto operativo de cultura, arte y literatura capaz de abarcar el ámbito de los fenómenos culturales y artísticos o abstraer incluso los rasgos fundamentales de todas sus manifestaciones. En el fondo, asistimos a una repetición moderna de la problemática que surgía alrededor de Platón y los sofistas. De todos modos, es evidente la suprema dificultad que representa esta vía que desemboca, por definición, en la confusión y el fracaso definitivo de toda fundamentación de la cultura y el arte $y$, en último término, de cualquier tema.

\footnotetext{
${ }^{3}$ Ibid., 310-311. (Traducción K. S.).

${ }^{4}$ Es el subtítulo del estudio de Kultermann.

${ }^{5}$ Ibid., 311.
} 
Por ello, desde mi punto de vista, se impone el retorno a fundamentos filosóficos más sólidos. Si no se reintroducen niveles de abstracción idóneos y distinciones constantes de la unidad y la diversidad que permitan una jerarquización ordenada, nos exponemos a un embrollo babélico.

Ahora bien, tampoco quiero sugerir con este ensayo - que se concibe estrictamente como ensayo- que para la definición del arte sólo existe esta solución única e inamovible; es más, soy consciente de que es susceptible de muchas correcciones y modificaciones. Lo único que pretendo es proponer una posible salida del laberinto de determinaciones efímeras que permita el retorno a una definición del arte consistente y a la vez abierta, con el fin de reunir en ella los elementos indispensables que integran el arte considerándolo en singular, como unidad y matriz adaptable a las diversas ramificaciones, es decir, una definición capaz de ofrecer mutatis mutandis la base para una puntualización posterior que se adapte a cada una de las artes particulares habidas y por haber. La concibo, por así decir, como la unidad que permite en ulteriores particularizaciones la inserción e integración de todas las diversidades de las diferentes artes.

Antes de entrar en materia podría ser de cierta utilidad aclarar que el arte no constituye un ente aislado y autónomo, sino que ha de ser incorporado y determinado en el ámbito mayor de la cultura. El arte se inserta como una de las posibles actividades humanas dentro del ámbito de la cultura y se alimenta de las características de ésta; sería difícil comprender qué es arte sin haber comprendido previamente qué es cultura.

Y llegados a este punto ¿cómo se puede abarcar la cultura como unidad sin claudicar ante la tentación de volverse historicista o relativista? Una base útil, aunque igualmente peligrosa, es la de confrontar a la antigua usanza natura y cultura, dicotomía capaz de acercarnos a la explicación de la problemática que nos preocupa. No interesa aquí detenernos en una definición extensa del concepto de naturaleza ${ }^{6}$; quisiera limitarme a su determinación como aquello que nos es dado y que funciona y se desarrolla sin la intervención del hombre; lo que no significa que la naturaleza no obedezca a leyes internas rigurosas. El ámbito de la cultura engloba todo lo producido por la intervención del hombre. La empresa no es fácil porque ninguna de las dos, por su intrínseca compenetración, puede deslindarse o diferenciarse rigurosamente ${ }^{7}$.

${ }^{6}$ Véase mi contribución «Natura y cultura: Una reconsideración de dos conceptos clásicos en su relación con la literatura», Urbs aeterna. Actas y colaboraciones del Coloquio Internacional Roma entre la literatura y la historia. Homenaje a la Profesora Carmen Castillo, Pamplona, EUNSA, 2003, 935-948.

${ }^{7}$ Véase 'Natur' en Historisches Wörterbuch der Philosophie, ed. por J. Ritter y K. Gründer, vol. 6, Darmstadt, Wissenschaftliche Buchgesellschaft, 1984, 421-478. 


\section{LA CULTURA}

El concepto de cultura que aplico se refiere tanto a las actividades y capacidades culturales como a los resultados y productos materiales e intelectuales que emanan de ellas. De entrada considero que la característica fundamental de las actividades y los productos culturales es el hecho de que aciertan a realizar y reunir de diversas maneras y medidas lo uno, lo verdadero, lo bueno y lo bello, es decir, para la definición del arte recurro a los transcendentales ${ }^{8}$. El hecho de que estos conceptos platónicos y neoplatónicos sean ya milenarios no significa que estén periclitados y sean inservibles. El problema surge más bien a causa de su naturaleza universal difícil de determinar, y que los sitúa más allá de todas las categorías que podrían facilitar su conceptualización. Ahora bien, esta limitación definitoria tampoco los vuelve inexistentes, al contrario, constituyen sin duda una de las escasas posibilidades de concebir la realidad más allá de las vicisitudes y variaciones fácticas e históricas que estamos acostumbradas a observar y padecer; los transcendentales nos liberan de la servidumbre de rendir culto a la contingencia.

No sólo resulta difícil la definición de los transcendentales, es igualmente complejo asir las innumerables emergencias bajo las cuales se nos presentan, tanto en la naturaleza como en la cultura, ya que son omnipresentes. No obstante, los estudiosos de las humanidades no pueden pretender ser más exigentes que los investigadores de las ciencias naturales para los cuales los fenómenos de la naturaleza tampoco se abren y se descubren por sí solos y a primera vista. La paciencia es, aparte de la curiosidad, una de las obligaciones más perentorias de todos los científicos, estudien la naturaleza o la cultura.

Que me perdonen los metafísicos si despacho con demasiada ingenuidad el tema de los transcendentales. Espero, sin embargo, que para nuestras necesidades resulten suficientes los datos fundamentales que se aducen. Habrá que adelantar que los transcendentales no son entes aislados, sino que se presentan y se manifiestan siempre juntos aunque sea en proporciones diversas. De esta manera no hay verdadera unidad sin verdad, bondad y belleza y, por supuesto, son válidas también las demás combinaciones.

Acaso lo más fácil sea descubrir e identificar el transcendental de la unidad en los entes en general y más palpablemente en las obras de arte. La unidad constituye uno de los aspectos sobresalientes y fundamentales de nuestras vivencias y experiencias. En la obra de arte lograda se mani-

${ }^{8}$ R. Alvira (2003, 17-28, cita 18), «Dimensión filosófica de las artes», Actas del Coloquio Internacional: Las artes y sus modos, Pamplona, Eunsa. 
fiesta con más transparencia la unidad, simultáneamente como perfección unificadora de sus partes y como reflejo y estímulo que se abre y nos abre la mirada hacia la unidad del ser. En tres ocasiones surge el fenómeno de la unidad en la obra de arte y, por tanto, también en la literaria: en primer lugar, la comunicación artística sólo alcanza su plenitud cuando la producción está completada por la recepción de una obra; en segundo lugar, la experiencia de la belleza culmina en la percepción de la unidad en la diversidad; finalmente, «en la mirada y en el disfrute se compenetran el elemento sensorial y el espiritual en una unidad profunda ${ }^{9}$, se compenetran el contenido bello y la percepción de la belleza. «El ser del ser es la belleza» afirma lapidariamente J. Lotz ${ }^{10}$.

No podemos, ni queremos esquivar la pregunta por la verdad. La bibliografía sobre este tema es inabarcable y en el cuadro de este ensayo es imposible y además innecesario tratar el tema con exhaustividad. Tan sólo quisiera dejar claro: la lengua es capaz de formular la verdad acerca de los fenómenos del ser y del ente y no representa solamente una estructura autorreferencial que produce sus propias realidades y relaciones no verificables. Lamentablemente la postmodernidad se complace a menudo en las afirmaciones de la imposibilidad de la existencia de la verdad y, de existir, de formularla verbalmente ${ }^{11}$. Asoma aquí otra reminiscencia del sofismo. En el fondo, los defensores de esta actitud deberían cuando menos tener remordimientos de conciencia, no sólo porque ellos mismos podrían experimentar serias dificultades de formulación de sus propios pensamientos, sino también y con anterioridad, porque de esta forma la realidad, también la suya, se vuelve insondable. La lengua ofrece la única manera de penetrar en la realidad, de sintetizarla y de sistematizarla, es decir, de descubrir la verdad, lo que equivale sencillamente a descubrir y describir las cosas como son. Describir el estado de las cosas a menudo resulta difícil y laborioso, pero no es por ello imposible, ni tampoco motivo suficiente para negar su existencia. Con paciencia y tiempo se irá completando el mosaico. De hecho, la historia de la humanidad se puede caracterizar como la historia de la paulatina y a menudo espinosa búsqueda de la verdad.

En el ámbito de la bondad se impone la apertura de una doble perspectiva que llanamente podría circunscribirse a la perspectiva dual del 'hacer bien' y la del 'hacer el bien'; dos ámbitos estrechamente relacionados aunque de matices diferentes. Hacer bien las cosas tiene que ver con la aspiración a la perfección que anima el quehacer del hombre en todas sus

9 J. B. LOTZ, Ästhetik aus der ontologischen Differenz. Das An-wesen des Unsichtbaren im Sichtbaren, München: Johannes Berchmans Verlag, 1984, 89.

${ }_{10}$ Ibid.

${ }^{11}$ Véase a este respecto la sugerente obra de G. STEINER, Presencias reales: ¿hay algo en lo que decimos?, Barcelona, Destino, 1998. 
facetas, y que anima sobre todo al artista que por lo general suele ser un perfeccionista inmisericorde consigo mismo.

La segunda faceta de la bondad, la del hacer el bien se refiere obviamente a la perspectiva ética que rige todo quehacer humano $\mathrm{y}$, por tanto, también el artístico. Con frecuencia surge la pregunta de si es bueno lo que se deduce de la naturaleza de las cosas y, sobre todo, de la naturaleza del hombre o si la bondad es sólo producto de las circunstancias y de las oportunidades; con otras palabras, la cuestión es si existen leyes naturales en el ámbito de las actividades humanas. He aquí las cuestiones elementales y, con ellas, nuestro problema. Es sabido que las opiniones acerca de este tema discrepan llamativamente y es urgente que volvamos a convicciones más razonables si queremos evitar que nuestra sociedad derive hacia su degeneración o incluso su disolución.

Puesto que ninguna actividad humana, y mucho menos la artística, se sitúa en un terreno de neutralidad ética, a la fuerza el ámbito de la creación ha de estar sometido a los postulados de la ética. Es grande la tentación de los artistas de buscar exclusivamente el bien hacer, la perfección formal de su obra y de olvidarse de su responsabilidad como personas y ciudadanos. Generalmente los artistas son perfeccionistas a ultranza, sin embargo, no viven y no pueden vivir en un «país de nadie» ético en el que se crean eximidos de respetar las normas obligadas de convivencia y de ética que se exigen de todo ciudadano. Ser artista siempre implica responsabilidad a la hora de producir una obra formalmente perfecta y también están llamados a respetar la dignidad del hombre. Su responsabilidad es aún mayor que la del ciudadano de a pie, puesto que pueden hacer un daño y también un bien mucho mayor por su capacidad de penetración, sus posibilidades de difusión y - no lo olvidemos- por el hecho de gozar de un elevado prestigio social.

Precisamente una de las consecuencias de la falta de normas y de respeto éticos es la situación en la cual se encuentra la sociedad occidental en nuestros días. El público está dispuesto a conceder a los artistas y pseudoartistas unas libertades de actuación casi ilimitadas. En nombre de la libertad se está fomentando el permisivismo olvidando que toda libertad, también la del artista, no es pensable ni practicable sin unos límites que constituyen la razón de ser de la libertad. El postulado actual del «everything goes» equivale, en el fondo, a la negación de la libertad por robarle la fundamentación: si no sé de qué estoy libre, forzosamente me encierro. Uno no tiene por qué ser moralista para descubrir y condenar estas anomalías, todavía más cuando están minando nuestras normas y valores de convivencia y civismo, sin los cuales una sociedad se transforma en un conjunto de individualistas irrefrenables y desesperados.

Dos palabras acerca de la belleza. Las reflexiones clásicas sobre la belleza la relacionan a menudo con el orden, el esplendor o el brillo de la 
forma. Forma no significa aquí necesariamente forma material, los fenómenos intelectuales también poseen forma y pueden ser bellos ${ }^{12}$. No es raro que la ejecución de una obra musical, un pensamiento, un argumento se designen como brillantes. En general, la belleza se descubre, tanto en la naturaleza como en los productos culturales, como una idea impregnada en una materia con una forma determinada. La discusión sobre la prelación entre la belleza natural y la artística es antiquísima y parece obedecer, entre otras cosas, a modas. El postulado de una imitación, a veces hasta de una reproducción fiel de la naturaleza, se opone al concepto de la creación genial como emancipación de las exigencias imitativas, como liberación de la servidumbre de la cercanía a la naturaleza. En este mismo momento conviven los dos extremos, por un lado, en la pintura hiperrealista y, por otro, en la no figurativa. Acaso la literatura sea el arte que menos posibilidades de alejamiento de la figuración posea. Las palabras significan ya antes de entrar en la plasmación literaria. Los intentos de «desfiguración» del llamado letrismo o poesía concreta pueden considerarse como experimentales y hasta fracasados.

¿Cómo debe concebirse una forma para que sea bella? Dado que la forma bella, al menos la creada por el hombre, es la forma de algo, es decir, es la forma de un fondo, la materialización de un tema y un contenido, uno de los criterios básicos de la belleza debe ser la configuración adecuada de un fondo que de por sí debe obedecer a los mandatos de la verdad y la bondad. No pocos estudiosos consideran que la belleza es la culminación de los transcendentales: la unidad, la verdad y la bondad confluyen ineludiblemente en la belleza. No cabe duda de que el conocimiento y la valoración de esta adecuación no se revelan la mayoría de las veces a primera vista ni con facilidad; no son raros los casos en los que las obras de arte se presenten crípticas y opacas o, por lo menos, de difícil acceso. Sobre todo en las artes no figurativas o no conceptuales como la música, la pintura o la escultura no figurativas, cuyo contenido referencial no se manifiesta inmediatamente a los receptores.

\section{LAS ARTES}

Como ya anuncié, quiero fundamentar mi definición de la literałura como arte sobre estos presupuestos, dado que el arte es uno de los ámbitos en los cuales se plasma la actividad cultural del hombre. Según la opinión más común y cotididana las artes forman el ámbito de la cultura por antonomasia por realizar más densa e intensamente los transcendentales. Gozan de un mayor prestigio, a pesar de que por justicia todas las actividades huma-

\footnotetext{
12 Véase también P. BlanCO, Estética de bolsillo, Madrid, Ediciones Palabra, 2001, 29 ss.
} 
nas en la medida en la que contribuyan a aumentar los conocimientos y la dignidad del hombre deban incluirse en el dominio de la cultura. Sobre todo porque esta atribución eleva el prestigio de la cultura en general y sirve de estímulo y a la vez de obligación en los quehaceres humanos, ya que cultura y arte destacan la responsabilidad de todos los implicados en los procesos culturales. Sobra insistir en el hecho de que el arte no es un fin en sí mismo, sino que su función fundamental es la de potenciar una mirada profundizadora sobre la realidad; es un sutil instrumento de conocimiento de la realidad y del hombre al lado de las demás disciplinas que tradicionalmente indagan de una manera $u$ otra en los enigmas que se le plantean al hombre.

Hemos llegado al punto en el que los elementos constitutivos de la actividad cultural tienen que servirnos de fundamento para una definición del arte. Propongo, pues, una definición basada en seis componentes que me parecen indispensables para una determinación mínima del arte.

Pero antes de emprender esta labor quisiera precisar que la voz 'arte' $\mathrm{y}$, por tanto, también la definición que propongo abarca dos realidades distintas, estrechamente vinculadas; por un lado, la capacidad del artista de crear obras de arte y, por otro, las mismas obras de arte, es decir, el resultado de la actividad artística. En términos aristotélicos, el arte es a la vez energeia y ergon. Rafael Alvira constata en este orden de ideas:

Por tanto: arte, en general, es el saber inscrito en la dimensión generativa o productiva del espíritu; arte bella es la capacidad de generar algo que aparece, con la intención de presencializar, de poner el énfasis en el esplendor continuo de la realidad, tras la mediación de la idea artística ${ }^{13}$.

Los seis componentes que acabo de anunciar están estrechamente relacionados pero no estrictamente jerarquizados, ello implica que en la práctica creativa tampoco deben realizarse en el orden indicado aquí; sin embargo, están presentes en todas las obras de arte.

Estos componentes son clasificables en tres grupos que llamaré componentes conceptuales, formales y funcionales. El componente conceptual «informa» la totalidad de la obra estimula y promueve la aplicación de todos los componentes en el sentido de dar forma. Lo designo con los términos convencionales de fondo y tema. Los tres componentes formales son el substrato, la modalidad y la genericidad. Finalmente, designo como componentes funcionales la comunicación y la ficcionalización.

Llamo conceptual el componente temático y de fondo por ser de naturaleza ideológica y por regir de una manera u otra la totalidad del quehacer creativo. Son componentes formales el sustrato, los modos y géneros

${ }^{13}$ R Alvira (2003, 23-25), «Dimensión filosófica de las artes», Las artes y sus modos. Actas del Coloquio Internacional, Pamplona, Eunsa. 
ya que suministran en la realización de cada obra modelos y procedimientos preestablecidos sin ser rígidos. Tampoco deben entenderse como preceptivos, no restan libertad creativa al artista y por tanto no imposibilitan la unicidad de cada obra de arte.

Llamo funcionales los componentes de la comunicación y ficcionalización por constituir las fases de adaptación de los modelos y procedimientos a la configuración final de cada obra y, posteriormente, su transmisión a los receptores. Son las fases de más proximidad y compenetración de lo artístico y lo artesanal: en ellas se manifiesta el dominio de las técnicas por parte del artista y su capacidad de aplicarlas en la configuración de la obra de arte.

Finalmente, cabe mencionar el aspecto funcional que designo como adecuación y que rige y encauza la labor del artista en la selección y aplicación de la totalidad de los elementos. integrantes de la obra de arte a lo largo del proceso creativo. Por tanto, no es un componente con una ubicación fija, sino un método y una norma de trabajo omnipresente. Acaso, apoyándonos en el término retórico de la inventio, habría que llamarla también invención, puesto que la búsqueda y conformación de los elementos constitutivos de la obra de arte es más que una mera adecuación en el sentido del ensamblaje de elementos ya presentes. Sin ninguna duda la adecuación-invención es el postulado más complejo en la creación artística por la infinitud de posibilidades técnicas y matizaciones que se revelan en cada acto creativo. Además, nunca es sólo una cuestión material de selección y estructuración sino que implica también una dimensión ética por plasmarse en cada obra la cosmovisión del artista.

La adecuación-invención se manifiesta, por tanto, como orquestación de los recursos artísticos en todas las fases con el fin de conseguir la plasmación apropiada de los requerimientos de la unidad, verdad y bondad que desembocarán en la emergencia de la belleza. Por tanto, no se debe entender como añadidura de elementos a un proyecto ya realizado, sino como el método de conseguir la perfección de la obra a través de la integración idónea de todos los componentes y procesos de elaboración. No hace falta insistir en que esta labor es particularmente sutil y compleja en la creación literaria.

\section{FONDO Y TEMA}

La introducción de este componente parte de la premisa de que la obra de arte y, desde luego, también la literaria, por muy difícil que resulte en algunos casos descubrirlo, siempre es expresión de algo, que la creación está guiada por el deseo y la intención de transmitir una idea, un mensaje. La obra de arte debe entenderse como transmisión materializada de un 
fondo, de una preocupación emanados de la cosmovisión del artista y guiados por el regulativo de los transcendentales. Ello implica que ya a estas alturas se inician decisiones sobre la verdad y bondad, es más se toman ya en la elección del tema, del fondo y su futuro desarrollo.

El proceso de creación artística esta constituído por la búsqueda y realización de la forma adecuada a este fondo. Tampoco es una fase aislable en algún punto del transcurso de la elaboración sino una exigencia permanente.

\section{El SUBSTRATO}

En el substrato de cada arte se inicia la transición de fenómenos y procesos espirituales hacia su materialización en objetos artísticos concretos, en obras de arte. El substrato es, por así decir, el puente entre la intuición o inspiración creadora y su posterior realización e incluso su ulterior interpretación en la recepción. Es el vehículo y soporte a través del cual se muestran, relacionan y valoran los elementos de la realidad plasmada en la obra de arte. Afirma R. Alvira:

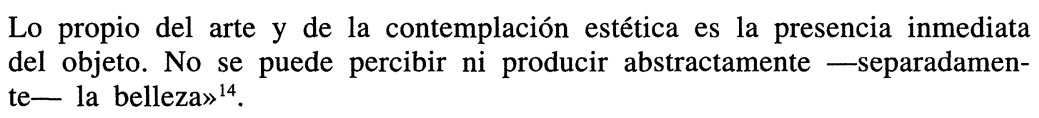

Por tanto, una de las características más palpables de las artes es su particular substrato puesto que cada arte realiza sus obras en y con materiales propios y característicos. Es decir, la obra de arte adquiere una forma que se manifiesta en una materia, incluso si esta materia es algo tan etéreo como los sonidos y el ritmo de la música. El artista hace surgir algo que entra en el ser a través de sus capacidades creativas como ya sugiriera Platón en el Simposio.

Ya es un lugar común que los artistas suelen quejarse de la insuficiencia del substrato que utilizan. Como lo que pretenden plasmar en su obra es una visión personal de la realidad, una vivencia subjetiva, es evidente que los matices que ofrecen los substratos, sobre todo el lenguaje en el caso del literato, nunca permitirá plasmar todas las matizaciones que, de por sí, son inefables. El rasgo particular y único del lenguaje como substrato de la literatura es su doble carácter de material fónico y conceptual. Es referencial y significa ya antes de entrar en configuraciones literarias, es además el instrumento de comunicación humana por antonomasia.

Evidentemente, el material utilizado determina el modo de hacer y las particularidades de la obra de arte; la obra musical no puede tener las

${ }^{14}$ R. AlviRA (1998, 35-36), La razón de ser hombre, Madrid, Rialp. 
mismas características que la literaria o la arquitectónica porque cada materia exige procedimientos específicos y tanto la una como los otros influyen decisivamente en la naturaleza y la estructura de las obras de arte.

No se trata de indagar aquí en los substratos de las diferentes artes, lo que importa es subrayar que a través del substrato la obra se transforma en un objeto sensorialmente perceptible que soporta la forma del contenido. La obra es, por así decir, la doble línea de sutura «objetual» entre los dos procedimientos espirituales de la creación y la recepción que es a su vez siempre también una especie particular de creación o, más exactamente, una recreación o concreación, como veremos más detenidamente en el capítulo de la comunicación en las artes.

El artista imprime su idea y su concepción de la obra en una materia y el receptor la transforma nuevamente en ideas e intuiciones, dejando que la obra surta efecto sobre su sensiblidad por medio de su capacidad interpretativa. Ello no quiere decir que la obra no posea un estatus propio; más allá de su función de puente, que une la intuición del autor con la del receptor, es un objeto autónomo. Es precisamente una característica de la obra de arte el que no se agota en la transmisión de un mensaje en que pierde después toda importantcia la configuración material, como ocurre, por ejemplo, con los textos e imágenes pura y meramente informativos o periodísticos. La obra de arte posee un valor propio como materialización de un fondo y conserva su esencia independiente en esta precisa combinación de materia y espíritu, quedando así disponible para otras recepciones $\mathrm{y}$ otras interpretaciones.

\section{LA MODALIDAD}

Al empezar este epígrafe me parece prudente aclarar previamente algunos de los términos técnicos que utilizaré. En la teoría de la literatura y en la de otras artes, la voz 'género' suele designar dos realidades y dos niveles de abstracción distintos: por un lado, designa la tríada tradicional de lírica, épica y dramática y, por otro, las divisiones de estos tres ámbitos (en las diversas artes son géneros, por ejemplo, la novela, la sinfonía, el retrato, el bajo relieve, etc.). Para evitar confusiones designaré 'modo' a la lírica, la épica y la dramática y reservaré la voz 'género' para las divisiones o eventuales subdivisiones de estos modos.

Los conceptos de modalidad y genericidad señalan el hecho de que las obras de arte, camino de su materialización u objetualización, forzosamente se encauzan a través de un modo y de un género. En las presentes reflexiones designa la incorporación y la adecuación de una obra a las exigencias de uno o varios de los modos. Entre las propuestas de una definición de la literatura como arte la de la modalidad es tal vez la más innovadora 
y por la misma razón también la más discutible, ya que su fundamentación en conceptos antropológicos es, cuanto menos, insólita.

Cada obra de arte, es más, cada actividad humana pertenece a un modo; siendo esto así se puede distinguir entre modos antropológicos y modos artísticos, muy estrechamente unidos por lo demás. Para una aproximación a los modos antropológicos echo mano de la teoría desarrollada por R. Alvira ${ }^{15}$. En ella se aleja de la tradicional fundamentación de los modos apoyada en los conceptos de sujeto y objeto o de lo subjetivo y lo objetivo como se ha venido practicando desde Hegel. Él propone la relación de la temporalidad como criterio decisivo, dado que

no se da en el ser humano ninguna acción meramente subjetiva, ni tampoco puramente objetiva. Sujeto y objeto son dos dimensiones de toda realidad: la una se refiere a la concentración unitaria (sujeto) y la otra a su relación con lo diverso (objeto). Cualquier realidad y cualquier acción tiene una dimensión subjetiva y otra objetiva, aunque el tipo de sujeto y de objeto sean diferentes, de diferente naturaleza, según la realidad de que se trate ${ }^{16}$.

En cambio, la dimensión temporal ofrece unas características más convincentes para la diferenciación de los modos en tanto que respuestas del hombre a las exigencias de la vida y de la realidad dado que

existir, para el hombre, es ser en el tiempo, es decir, ser sintetizando el tiempo, pues éste no es algo meramente externo a nosotros. Vivimos en presente cargando con nuestro pasado y proyectándonos hacia el futuro ${ }^{17}$.

He aquí la base sobre la cual quiero desarrollar la teoría ${ }^{18}$ de los modos artísticos derivados de los antropológicos. Veamos, pues, muy someramente una caracterización de los tres modos como conceptos antropológicos y artísticos.

En la creación artística la modalización como incorporación de una obra en uno o varios modos corresponde a una fase intermedia entre lo puramente conceptual y lo potencialmente formal, por un lado, y las concreciones objetuales de la obra, por otro. En el recorrido desde la inspiración hasta la realización de la obra de arte, lógicamente en un determinado punto o acaso en una determinada fase de transición los componentes espirituales e intelectuales van transformándose en elementos estructurales y materiales. Muy probablemente habrá que imaginarse el proceso como un desarrollo gradual. A estas potencialidades configurativas pertenecen los modos y

${ }^{15}$ R. Alvira (2001, 11-16), «Los modos como dimensiones antropológicas», Actas del Coloquio Internacional 'Los géneros en las artes', ed. K. Spang, Pamplona, Universidad de Navarra.

16 R. AlviRA (2001, 11-12).

${ }^{17}$ Ibid. (2001, 12).

${ }_{18}$ Véase K. SPANG, «A vueltas con la cultura y el arte», Pensamiento y cultura, 4, 2001, 191-200. 
géneros como unidades que posibilitan las diversidades y multiplicidades de las obras concretas que, proyectadas y elaboradas, se convierten a su vez en unidades, además unidades con una entidad simultáneamente sólida e insólita si se las compara con la fugacidad y la inconstancia de los fenómenos naturales.

Ahora bien, los modos todavía no generan los modelos o estructuras específicos; su tarea se limita a la canalización de la inspiración creativa hacia moldes particulares que reciben su forma definitiva en el género. Los modos son, por así decir, la condición de la posibilidad del surgimiento de los géneros. De ellos nos ocuparemos en el próximo apartado.

\section{La lírica}

En la lírica predomina la dimensión temporal del pasado; ahora bien, no se trata del mero tiempo pasado, sino de lo que R. Alvira llama «anterioridad interiorizada». Esta interiorización no es equiparable a la mera cronología de experiencias vividas, sino que presupone una labor de síntesis, una especie de memoria transcendental con el resultado de que el pasado se transforme en propiedad y conocimiento individual. Existencialmente la lírica se manifiesta en la aspiración de asimilar y de «hacer suyo» el tiempo, de no dejarlo pasar y menos aún de matarlo.

La lírica en el arte refleja la interiorización como profundización reflexiva y contemplativa en experiencias del pasado y su universalización en la obra. A menudo surge la impresión de que en la obra lírica no pasa nada, que el tiempo se demora; y de hecho la lírica funciona como memoria que condensa vivencias y experiencias en recuerdos esencializadores; como consecuencia, la actividad lírica prescinde de lo anecdótico y lo marginal. En las obras líricas de todas las artes llama la atención la frecuencia de las dimensiones reducidas y el afán de insistir en matices de lo mismo. Aunque lo lírico se debe entender como soledad contemplativa y reconfortante, una manera de escuchar hacia dentro, y también de consentir y sintonizar con el otro y lo otro, nunca debe desembocar en un sentimentalismo particularizante. Si le falta la dimensión universal no es auténtica lírica, es decir, la vivencia individual debe trascenderse y convertirse en experiencia de lo humano.

Lo musical y rítmico desempeñan un papel destacado en la creación lírica no sólo en la música y la literatura. En la música los adagios son predominantemente líricos. En la lírica literaria la esencialización se refleja palpablemente primero en el estatismo y luego en la profundización organizada musical y rítmicamente como verdadero tema con variaciones, como dando la vuelta al tema en constantes revelaciones de facetas nuevas. 


\section{La épica}

La dimensión temporal de la épica es el futuro como anticipación del porvenir, como tarea, empresa y objetivo, es decir, lo épico se manifiesta en la plasmación de un proyecto dinámico de existencia. No faltan los ingredientes líricos puesto que cada proyecto arranca en el pasado como recuerdo de experiencias vividas que forman base y estímulo para proyectos y empresas que se realizarán en el futuro con vistas a la consecución del objetivo. Por tanto, implica la superación de obstáculos y la solución de conflictos.

Las empresas suponen una planificación estratégica previa para conseguir el objetivo propuesto. Siempre implican la necesidad de superar obstáculos, de hallar la solución a conflictos. El propósito de realizar unos objetivos exige una mentalidad empresarial, la capacidad de planificar estratégicamente actuaciones y, en cierto sentido, la anticipación del futuro.

La épica es el quehacer de la vida, para decirlo al estilo de Ortega y Gasset. Ella presupone la lírica en el inicio. [...] El futuro verdadero es lucha, trabajo, construcción, realización de futuro o futuro real ${ }^{19}$.

En las artes no sólo la epopeya literaria es épica, las otras artes pueden plasmar igualmente sus obras con formas y procedimientos épicos. Siempre cuando surge la impresión de que la obra representa la superación de obstáculos, la pugna con dificultades de llevar a cabo un proyecto entonces se hace notar lo épico. Así ocurre en la escultura del Laocoonte, en la representación pictórica de luchas y batallas: así lo sugieren los puentes y rascacielos en la arquitectura. Lo épico se presenta frecuentísimamente en la música; casi todas las sinfonías tienen por lo menos un movimiento épico. Un ejemplo modélico es el primer movimiento de la Quinta Sinfonía de Beethoven. Pero es también épica la moderna música rock con sus ritmos y su volumen pujantes y denodados.

Sin embargo, la plasmación más palpable de lo épico se presencia en la literatura. En casi todas las narraciones se configuran proyectos de vida y procesos existenciales como relatos en los que unas figuras se mueven en un tiempo y un espacio teniendo que superar obstáculos y solucionar conflictos. La orientación hacia el futuro es del todo evidente, incluso si el conflicto propuesto no encuentra solución y permanece abierto.

\footnotetext{
${ }^{19}$ R. AlviRA (2001, 14).
} 


\section{La dramática}

Como dimensión temporal, lo dramático se sitúa principalmente en el presente. R. Alvira caracteriza la dramática antropológica de la siguiente manera:

Por otra parte ese misterio del presente humano, que física y psicológicamente parece escaparse siempre y que, sin embargo, es el aire de nuestra existencia, tiene momentos de mayor inclinación lírica y otros más bien épica ${ }^{20}$.

Por tanto, la dimensión temporal de la dramática es el presente pero arranca en el pasado y mira hacia el futuro. Dada la precariedad del concepto de presente con su duración teóricamente inexistente, como modo antropológico hay que imaginarse lo dramático como una especie de diálogo o interludio entre el pasado y el futuro. Eso implica también que en la dramática confluyen los tres modos con dimensiones temporales particulares. Lo dramático es en gran medida configuración de lo efímero, pero no como simple desaparición de los fenómenos existenciales, sino como captación sintetizante de lo pasajero. Son especialmente dramáticos el diálogo y la discusión; también lo es el juego, no tanto en lo que supone de diversión y entretenimiento sino en la necesidad y el despliegue de reglas que hacen posible el juego y a las que los jugadores deben atenerse, ya que su cumplimiento o incumplimiento tendrá consecuencias en el futuro. También son dramáticas las fiestas por lo que tienen de implicaciones ceremoniales, de desarrollo de una determinada conducta.

Lo dramático como presente arranca en el pasado y mira hacia el futuro; es una especie de diálogo entre lo que pertenece al pasado y lo que va a venir. He aquí una de las razones por las que el montaje de una obra teatral se designa como representación, como volver a hacer presente. A la fuerza se reúnen en la dramática los tres modos con sus dimensiones temporales particulares. Los actores en el teatro 'juegan' un papel; en este orden de ideas viene a la memoria la comparación del mundo y de la vida con el teatro, el theatrum mundi, el mundo y la existencia como juego. Es dramático también el deporte, el banquete y todo lo que tiene que ver con lo festivo, lo culinario, la perfumería y la moda. Lo gustativo y lo olfativo son efímeros y huidizos por naturaleza, los platos y los vinos más exquisitos producen un placer efímero.

\footnotetext{
${ }^{20}$ R. Alvira (2001, 15).
} 


\section{LA GENERICIDAD}

La presencia de elementos constantes y variantes puede observarse en todos los niveles de abstracción que estamos manejando en este ensayo, desde el nivel más general de la cultura hasta las obras concretas, se descubren permanentemente diversas combinatorias de constantes y variantes.

Así ocurre también con los géneros en las artes que son frutos de la observación de constantes y variantes en grupos afines de obras de arte. Además el género es concebible como ergon y energeia, es decir, por un lado como obra concreta realizada según un determinado modelo y, por otro, como potencialidad y posibilidad de plasmación. Se sitúa entre el modo como cauce creativo todavía no formalizado y la obra concreta como unidad que realiza las determinaciones conceptuales y formales preestablecidas y caracterizadas por su gran flexibilidad.

Ontológicamente el género se concibe como ente conceptual o ideológico que regula la relación entre unidad y diversidad, respondiendo así al afán racional del hombre de crear límites y unidades. Siempre cuando a través de la repetición ordenada de elementos diversos emerge una unidad o entidad reconocible y repetible se puede hablar de género. En las artes la unidad creada por el empleo reiterado de rasgos constantes se convierte en molde de uso repetido o género artístico. Como ya advertí, no deben concebirse como unidades estancas, inflexibles e inamovibles - la flexibilidad forma parte de su carácter instrumental - sino que responde al constante deseo de innovación de los artistas que ensayan continuas interferencias e innovaciones. La única condición para que se pueda seguir hablando del mismo género es que se conserven algunos rasgos constantes imprescindibles para su identificación. Esta circunstancia dificulta los estudios genológicos pero constituye también su fascinación. Además, el concepto y la práctica del género artístico es de suma utilidad en la creación y la recepción de la obra concreta, puesto que en su emergencia facilita y encauza su creación y en la recepción posibilita y orienta la aproximación interpretativa.

¿Y qué es un género? La bibliografía sobre este tema, sobre todo en el ámbito de los géneros literarios es desbordante ${ }^{21} \mathrm{y}$, a pesar de todo, parece que la genología tiene todavía un largo camino que recorrer hasta encontrar definiciones y tipologías convincentes y métodos de análisis satisfactorios. En el cuadro de este estudio me limitaré a esbozar los aspectos indispensables dado que la pertenencia de los productos artísticos a un género es uno de los aspectos definitorios fundamentales del arte. Los géneros pueden caracterizarse muy someramente como moldes formales repetibles

${ }^{21}$ K. SPANG, Los géneros literarios, Madrid, Síntesis, 1993. 
y flexibles que constituyen plasmaciones específicas dentro de los diversos modos.

Por tanto, el género es una combinatoria flexible de constantes y variantes de varia índole. Para que haya género debe haber un cierto número de elementos fijos. (Por ejemplo, y hablando de un género literario, para que haya novela debe haber un narrador y una historia extensa que a su vez se compone de figuras, tiempo y espacio). Cada una de estas constantes es realizable de diversas maneras y comprende, por tanto, ya unas variantes internas ampliables por otras externas. Ilustraremos el primer caso con las constantes de narrador e historia: es sabido de todos que existen numerosos tipos de narrador y numerosas posibilidades de realizar figuras, tiempo y espacio en una narración.

También por este motivo los géneros deben considerarse como moldes flexibles. En su caso pueden surgir subgéneros si alguna o varias de las variantes se convierten en constantes de este subgénero. Eso ocurre, por ejemplo, con la novela epistolar, que tiene como constante definitoria una de las variantes de narrador, a saber, la del autor de cartas. También se da el caso de la introducción de nuevas variantes, un hecho que nos permite, entre otras cosas, rastrear la evolución histórica de los géneros a través del análisis diacrónico de determinadas variantes que, sin alterar por ello las constantes, han podido entrar, por las razones que sean, en una configuración genérica determinada.

Urge reiterar el hecho de que la configuración de una obra dentro de los moldes de un género no la priva de su unicidad característica. Cada obra de arte es irrepetible, pero este hecho no debería conducir a la suposición de que es radicalmente única e incomparable — como sostenía Croce respecto de las obras literarias-. El género es precisamente un aspecto que comparten todas las obras de arte formando así grupos con rasgos comunes que permiten su comparación. Estos rasgos no pueden compararse con las estructuras deterministas de la biología o la física; no se trata de negar la libertad creativa al artista que se mueve siempre de forma independiente entre las numerosas posibilidades que ofrecen las combinatorias genéricas y que incluso añade rasgos no legislados hasta el momento. Los sustratos, los modos y los géneros constituyen una especie de delimitación natural de las potencialidades creativas. Y si últimamente se ha puesto de moda cultivar el 'transgénero' en el sentido de la mezcla de dos o varios géneros, tampoco se niega con ello la existencia del género, sino que se afirma su vigencia y además la libertad creativa que inevitablemente se vincula siempre de una manera o de otra con el género.

Se debe insistir en el hecho de que la pertenencia de una obra a un modo y un género posibilita y facilita enormemente su recepción. Por ello no sólo los artistas, sino también los receptores de sus obras deben estar familiarizados con los fenómenos modales y genéricos. No leemos libros o 
literatura a secas, sino novelas o cuentos, no escuchamos simplemente música sino sinfonías o un cuarteto de cuerdas, no miramos pintura, sino un retrato o una naturaleza muerta. Si el receptor no cuenta con los preconocimientos pertinentes su recepción resultará deficiente y el conocimiento y el gozo disminuirán. El hombre es, por así decir, un ser genérico (y no sólo en la emisión y recepción de obras de arte); precisa estas unidades genéricas preestablecidas para poder dominar la multiplicidad de la realidad artística y también la cotidiana. En la recepción artística la falsa atribución genérica puede conducir incluso a malentendidos e interpretaciones erróneas.

\section{LA COMUNICACIÓN}

Toda actividad humana es de alguna manera comunicativa, toda actividad dice consciente o inconscientemente algo sobre el que la realiza y revela igualmente algo sobre el resultado de esta actividad. El arte posee una orientación específicamente comunicativa; las dos facetas -la comunicación humana en general y la artística como uno de sus aspectos- son manifestaciones privilegiadas y expresión de nuestra condición de seres sociales. El arte comunica conectándonos con el mundo, crea una especie de puente entre la realidad y los receptores; lo que la realidad quiere y puede comunicarnos lo logra condensar el buen artista en su obra. La comunicación en las artes presupone lógicamente la existencia de un emisor que desencadena y configura la comunicación a través de la obra de arte y la de un receptor al que va destinada y que la interpreta.

Como vimos ya con anterioridad, la percepción y la interpretación de una obra de arte no se realizan nunca sin la colaboración creativa de los receptores, no existe una recepción radicalmente pasiva, neutra e imparcial. Cada receptor aporta preconocimientos o 'prejuicios' - en la conocida terminología de Verdad y método gadameriana- y naturalmente contribuye con sus capacidades interpretativas a personalizar e individualizar la recepción de la obra de arte. Es así como se completa la unidad comunicativa de la obra de arte. Sin embargo, la obra no es jamás totalmente abierta como ha querido sugerir en un primer momento $\mathrm{U} . \mathrm{Eco}^{22}$ teniendo que frenar más tarde el entusiasmo emancipador del lector ${ }^{23}$.

La recepción artística se puede concebir como un puente que une a un sujeto emisor con un sujeto receptor. Es lo que hace posible la transformación del objeto artístico, que se debe entender como la obra acabada tal

${ }^{22}$ U. ECO, Opera aperta, Milano, Bompiani, 1964; versión esp. Barcelona, Seix Barral, 1963 y Lector in fabula. La cooperazione interpretativa nei testi narrativi, Milano, Bompiani, 1979; vers. esp., Barcelona, Lumen, 1987.

${ }^{23}$ U. ECO, I limiti dell'interpretazione, Milano, Bompiani, 1990. 
como sale de las manos del artista, y que sólo se convierte en objeto estético a través de su recepción. Es decir, la función comunicativa de la obra de arte se cumple sólo al completarse la relación emisor-mensaje-receptor que genera una especie de circularidad de comunicación, puesto que la recepción implica el establecimiento de una conexión entre receptor y emisor, aunque no sea directa y explícita. Emisor y receptor se precisan mutuamente pero la completa independización de uno u otro falsifica la comunicación, lo mismo que la independización del mensaje. La recepción literaria. en la inmensa mayoría de los casos, se constituye como comunicación diferida en el sentido de un sermo absentis ad absentem, como la llamaron los retóricos clásicos. Es decir, el receptor no está presente a la hora de la emisión, ni el emisor en el momento de la recepción.

\section{LA FICCIONALIZACIÓN}

No es casual que el apartado dedicado a la ficcionalización en el arte aparezca en último lugar e inmediatamente después de tratar la comunicación. Hablar de la ficcionalidad en este lugar significa, por un lado, que todos los aspectos mencionados dependen en mayor o menor medida de la labor ficcionalizadora del artista. Por otro lado, he querido destacar que la propia actividad es fundamental en el quehacer del artista. Sin ficcionalización ni hay creación artística ni obra de arte. Con otras palabras, la labor creativa que llamamos adecuación de la forma a su fondo se realiza en gran parte con los diversos recursos de ficcionalización de los que dispone el artista.

Quiero subrayar también que la ficcionalización no es un procedimiento más en el proceso creador, sino que está presente desde el primer momento hasta la terminación de la obra. En cierto sentido sigue en vigor hasta en la recepción, que es equiparable a un nuevo proceso de ficcionalización porque, como vimos al hablar de la comunicación, la descodificación debe comprenderse como colaboración y con-creación que resulta más intensa aún en la recepción de la obra literaria en la que el receptor tiene que «construir» el mundo que le presenta el autor a través de la palabra.

La ficcionalización en la creación se manifiesta como una orquestación eficaz de los recursos artísticos en todas las fases de su génesis, hasta recibir una forma apropiada a los diversos aspectos y matices de la unidad, la verdad y la bondad; una orquestación que, realizada con la debida pericia, desembocará necesariamente en belleza. La belleza de una obra de arte no es consecuencia de la añadidura de elementos nuevos a los componentes ya existentes, sino que es la perfección que nace de la lograda y apropiada integración de todos los componentes y procesos de elaboración de la obra de arte. 
Para poder comprender mejor el proceso de adecuación de fondo y forma a través de los recursos de ficcionalización conviene aclarar someramente los conceptos de ficción, ficcionalidad y ficcionalización.

El único de los tres términos que figura en el Diccionario de la Real Academia es el primero: 'ficción', que se explica en su primera acepción como «acción y efecto de fingir». Precisamente para distinguir entre acción y efecto de este 'fingimiento' introduzco los dos neologismos de 'ficcionalización' y 'ficcionalidad', el primero para designar la actividad artística de crear ficción, diferenciándolo de 'ficcionalidad' que designa el efecto y resultado de esta actividad y que desemboca en un alejamiento mayor o menor de la realidad representada o aludida en la obra de arte en comparación con lo que designo tautológicamente como 'realidad real'.

El arte refleja de manera imponente la capacidad humana de selección y de síntesis de elementos de la realidad que hacen posible el acceso al ser. Constituye el aspecto creativo que obliga al artista a demostrar su habilidad de penetrar la superficie de lo fáctico y de captar la presencia de los transcendentales y materializarla mediante sus destrezas imaginativas y creativas. F. Gómez Redondo afirma a este respecto:

La ficción no tiene que ser concebida como lo no-real, sino como uno de los medios más valiosos de poder conocer la realidad. La ficción no es lo contrario a lo real, sino precisamente la imagen que de lo real puede constituirse. Es más: la ficción es la única imagen de la realidad que puede conocerse. $\mathrm{O}$ lo que daría igual: a través de la ficción, el individuo puede ponerse en contacto con la realidad que le rodea ${ }^{24}$.

Puesto que la ficcionalidad no es un fin en sí mismo - la pretensión del buen artista no es la de volver extraña o divertida la presentación de un mundo inventado e inexistente- la verdadera ficcionalización aspira a penetrar más hondamente lo puramente fáctico y fenoménico de las percepciones. No se limita a la mera reproducción servil, sino que está destinada a abrir una mirada más esencial sobre el hombre y el mundo; es otra forma de la verdad, como afirma San Agustín diciendo «cum autem fictio nostra refertur ad aliquam significationem, non est mendacium sed aliqua figura veritatis» ${ }^{25}$. Natural y desgraciadamente no se puede excluir la posibilidad de abusos de la ficcionalización para presentar realidades intencionalmente deformadas y alienadas.

Va sin decir que ningún artista será capaz de descubrir y de configurar la verdad entera; su verdad y la de sus obras será siempre una verdad parcial e incompleta; no obstante no deja de ser auténtica verdad sólo porque sea parcial. Lo más significativo del proceso ficcionalizador del arte es que el

${ }^{24}$ F. Gómez REdondo (1994), El lenguaje literario. Teoría y práctica, Madrid, Edaf, 127-128.

${ }^{25}$ SAn Agustín, Quaestiones Evangeliorum, 51, PL 35. El subrayado es mío. 
artista no se halla tan atado al mundo real como el filósofo que tiene necesariamente que dar cuenta del mundo tal como es fenoménicamente. En cambio, el artista crea su propio mundo de manera relativamente independiente y puede mostrarlo tal como debería ser, como ya lo requería Aristóteles en su Poética ${ }^{26}$; se le concede por convención la libertad de escoger el tema y los ingredientes adecuados para plasmar el mundo según su visión.

La obra de arte no es verdadera en cuanto reproducción de una realidad existente, pero sí en cuanto proyecto de un mundo que corresponde a la verdad óntica o transcendental. También es el caso allí donde el artista recurra a la representación de lo inauténtico, lo injusto y lo feo, con la sola condición de que lo inauténtico se reconozca como mentira, lo injusto como abusivo y lo feo como consecuencia de la falta de verdad y bondad. El Guernica picassiano es un flamante ejemplo de ello. A veces la mostración del revés feo y falaz de la moneda resulta más adecuado y surte más efecto que no el lado agradable y pulido porque resalta la carencia.

La ficción auténtica no tiene nada que ver con la intención de endulzar la realidad o de inducir al error, sino que constituye un medio artístico, quizá incluso el medio por antonomasia, capaz de superar la contingencia y las continuas transformaciones de los fenómenos para configurar así las verdaderas constantes del ente y del ser. La ficción erige diques contra el fluir y el devenir permanente de las cosas creando un mundo posible invariable; en el fondo - $y$ no es una contradicción-, la ficción inmoviliza el tiempo y el espacio para permitir una mirada allende la superficie de las apariencias, para abrir la visión sobre el ser de la realidad.

La posibilidad de inventar mundos y conflictos posibles que no tienen por qué obedecer a la estricta causalidad espacial y temporal ofrece a la vez la posibilidad de alejarse de lo rígidamente individual y concreto para alcanzar un grado más elevado de universalidad y representatividad. Así, el problema de Hamlet no es únicamente el problema de Hamlet, un retrato no es sólo la representación de una persona concreta; detrás de ambos y detrás de cada representación artística de un hombre y un ambiente se trasluce el hombre y el mundo.

Por razones obvias, la ficcionalización no es nunca una creación ex nihilo en el sentido de que se invente una realidad radicalmente nueva, y menos en la literatura, por el mero hecho de que las palabras de por sí remiten a la realidad existente. El artista siempre echa mano de elementos del mundo real porque es la única manera de poder identificar en la recep-

${ }^{26}$ «Es evidente también que no es obra de un poeta el decir lo que ha sucedido, sino qué podría suceder, y lo que es posible según lo que es verosímil o necesario. Pues el historiador y el poeta no difieren por decir las cosas en verso o no (...) sino que difieren en que uno dice lo que ha ocurrido y el otro qué podría ocurrir. Y por eso la poesía es más filosófica y noble que la historia, pues la poesía dice más bien las cosas generales y la historia las particulares» (1451 b). 
ción el mundo imaginativo y, a través de él, el mundo auténtico que pretende mostrar y que permite reconocer el ser más allá de la facticidad evocada. Conocer es siempre reconocer y este redescubrimiento y esta recreación no son siempre fáciles. Con frecuencia la interpretación de una obra de arte plantea arduos problemas; el peligro de la opacidad existe ya en un arte conceptual como la literatura, la pintura y escultura figurativas que todavía representan realidades parecidas a las acostumbradas; pero en las artes plásticas no figurativas existen obras que no sólo alienan el mundo representado sino que se alejan completamente de elementos reales identificables. Ello no significa que una mancha de color, un volumen cualquiera, un determinado trazado de una línea no puedan tener fuerza expresiva. Es actuar demasiado a la ligera condenar sin más todo arte no figurativo sólo porque aparentemente se cierra al acceso; ahora bien, es cierto que con frecuencia ofrece un margen de interpretación demasiado amplio y exige del receptor una colaboración mucho más intensa que el arte figurativo.

Kandinsky afirmó que las artes deberían aproximarse a la música. Es precisamente en la música donde la identificación y la recreación del tema y del contenido resultan mucho más espinosas. Pero esto no significa que el compositor no tenga nada que decir; pretende, cuando menos, transmitir un estado de ánimo, una emoción, un sentimiento. Incluso un receptor sin experiencia puede distinguir entre una melodía triste y otra alegre.

Como subrayé con anterioridad, no es imaginable una actividad humana en la cual no participen de una manera $u$ otra y en mayor o menor medida los transcendentales. Lo que distingue las actividades, por así decir, normales de las artísticas es la proporción en la que hacen transparente el ser. Incluso dentro de las artes se reconoce al buen artista por su mayor capacidad de crear un cierto equilibrio entre las exigencias que le imponen los transcendentales. Sin embargo, abundan también obras que insisten demasiado en la unidad y marginan así el hecho de que sin diversidad no puede haber unidad, ni en la realidad ni en la obra de arte; otras hacen alarde de verdad y se arriesgan a producir la impresión de ser frías y cerebrales, otras insisten demasiado en la bondad y se transforman en tratados moralizantes y, finalmente, existen autores y obras que cultivan en exceso la belleza y tienden a ser pobres de contenido y terminan por ser parcial o completamente objetos decorativos. El objetivo del artista debe ser encontrar el «punto» al modo del cocinero que busca el equilibrio más armonioso entre todos los ingredientes de un plato.

En este orden de ideas surge - como en la Crítica de la razón práctica kantiana- la discusión acerca de los conceptos de utilidad e inutilidad, como criterios de diferenciación y valoración entre el producto artesanal, por un lado, y el artístico, por otro. Si el concepto de utilidad significa valor de uso de un objeto, la obra de arte lógicamente no tiene utilidad. 
En cambio, la evocación y la transmisión de verdad, bondad y belleza son enormemente útiles en tanto en cuanto son los alimentos espirituales de los que precisamos todos, tanto o más que del alimento corporal. Se trata de dos niveles de abstracción y no debe confundirse el más inmedidato valor de uso material y el valor intelectual y espiritual que en el arte es indudable.

Un capítulo sobre la ficcionalización como proceso de adecuación de forma y contenido en el arte no puede ser explícito ni detallado, por la simple razón de que es precisamente en este ámbito donde existen las diferencias más llamativas entre las diversas artes y los recursos más numerosos. Sin embargo, quizá sea operativa la consideración de los dos aspectos del objeto y del modo de ficcionalización.

Por este motivo divido la ficcionalización en dos grandes ámbitos; en primer lugar, los elementos de la ficcionalización que entran en la configuración de la obra de arte, es decir, la transformación a la que se somete la realidad mediante el substrato y los demás ingredientes de una obra de arte. Un paradigma palpable de esta intervención se observa en la literatura puesto que en ella se plasman unas figuras en un ambiente espacio-temporal y unas vivencias similares a las del mundo real, si bien configuradas como simulacro, como mundo y conflicto posibles. Lo mismo ocurre en la pintura y la escultura figurativas.

En segundo lugar y muy vinculada con esta ficcionalización, por así decir 'material' debe considerarse el modo de ficcionalizar, las actitudes y los procedimientos que se consideran para crear este mundo posible. En este orden de ideas J. B. Lotz ${ }^{27}$ propone en su estudio de estética dos actitudes fundamentales frente a la obra de arte y la creación artística: el 'objetivismo y subjetivismo ónticos' que constituyen dos extremos entre los cuales se sitúan innumerables variaciones posibles.

El objetivismo parte del presupuesto de que el arte es tanto más arte cuanto más imita la naturaleza y lo dado; de allí su denominación de objetivismo óntico porque tiende a reproducir fielmente la realidad. Podría también llamarse realismo o naturalismo, dado que su meta es la aproximación exacta a la naturaleza. En este tipo de ficcionalización el grado de ficcionalidad resultará muy bajo, dado que el artista busca la cercanía con la realidad. El filósofo alemán advierte en esta actitud extrema del riesgo de pérdida de profundidad en lo mostrado en la obra porque se limita casi exclusivamente a la representación de la superficie ocultando así el ser. Lo que parece interesar al artista en este modo de ficcionalizar es hacer gala de sus capacidades artesanales; evidentemente, el dominio de las técnicas artísticas tampoco constituye un obstáculo en la realización de una obra de arte lograda; al contrario, puede facilitar notablemente la tarea. Es más, sería deseable que muchos artistas actuales tomasen más en serio esta faceta de su quehacer creativo, de esa estrecha relación que existe entre el arte y lo artesanal.

${ }^{27}$ J. B. LOTZ (1984, 100-111). 
En cambio, el subjetivismo óntico aspira a la expresión de las vivencias y emociones individudales del artista. Su arte no representa los objetos tal como son en realidad, sino solamente como se le revelan en su visión personal, en las emociones y los sentimientos que provocan en su alma. Incluso puede apartarse completamente de toda plasmación objetual y figurativa provocando una especie de narcisismo que consigue que se descuide o se pierda totalmente el mundo objetivo. En vez de un diálogo con la realidad el artista realiza un yermo monólogo consigo mismo.

Tanto un extremo como el otro son nocivos para el artista y su obra; lo que no quiere decir que tanto las capacidades artesanales como el autoescrutinio no sean útiles para la creación artística; tanto la cercanía como el alejamiento del objeto, tanto el distanciamiento como la atención a las reacciones de la propia sensibilidad pueden ser estimulantes y fecundos; lo importante es, como siempre, encontrar el punto medio, el equilibrio adecuado a cada obra ${ }^{28}$.

Evidentemente, ninguna ficcionalización y adecuación pueden ser perfectas, son siempre y por naturaleza aproximaciones más o menos logradas. Siempre existirán varias formas de ficcionalizar un tema o de adecuar fondo y forma. Ficcionalizaciones diferentes suscitarán también reacciones diferentes a la hora de su recepción. Por tanto, habrá que conceder siempre un margen de actuación tanto a la emisión como a la recepción. Sin embargo, el margen de creación y de recepción nunca es ilimitado, arbitrario o absolutamente subjetivo; siempre debe conservar por lo menos una porción de intersubjetividad, ofrecer pistas mínimas para la identificación del mensaje. Ahora bien, la preferencia del artista por una adecuación u otra no se puede siempre explicar en términos racionales, a menudo ni él mismo puede rendir cuentas de su quehacer; la creación tiene sus razones que la razón ignora, podríamos precisar, modificando la conocida sentencia de Pascal. Frecuentemente las predilecciones personales juegan un papel importante, tanto en la producción como en la recepción, pero los gustos no pueden nunca justificar la presunta imposibilidad de establecer criterios a propósito de lo bello y lo feo, los dos son objetivables e inter subjetivos.

${ }^{28}$ J. L. GONZÁLEZ QUIRÓs, Repensar la cultura, Pamplona, Ediciones Internacionales Universitarias, 2003, 224-225, critica dura pero acertadamente la presunción creadora y la superficialidad artesanal de muchos artistas actuales: «No se trata solamente de complicaciones metafísicas, de que a los artistas y creadores les haya dado en un ataque de pretenciosidad, por decir que lo suyo es fabricar universos o proponer profundos enigmas a la consideración del público, en lugar de cultivar con esmero su propio oficio, sino de cosas mucho más inmediatas, como, por ejemplo, el desconcierto absoluto que supone la ruptura de las categorías y las especialidades, la mescolanza caótica de los géneros, el derrumbarse de los cánones, la hibridación de todo con nada, la perdida de aprecio por el buen oficio, la absoluta ilegibilidad de muchas propuestas, fenómenos que de una y otra forma acontecen en todas las manifestaciones de la cultura, desde la pintura o la música hasta el cine y la literatura». 


\section{CONCLUSIONES}

Vuelvo a insistir en que este ensayo en el que intento aportar alguna luz sobre un tema tan pretencioso y espinoso. Partiendo o no del hecho literario, la definición del arte no puede ser más que una aproximación y requiere todavía pulimiento y no pocas matizaciones antes de que se puedan consolidar los resultados. En ello sigo fielmente los lemas que introducen este trabajo.

Tal vez haya podido verse durante el recorrido del camino cuáles son las dificultades que conlleva la elaboración de una teoría que abarque no sólo las diversas artes, sino que evite también los numerosos escollos que opone a ello el espíritu del tiempo. En una época en la que la especialización y la atomización, y más aterradoramente aún, el relativismo, han alcanzado unas cotas imprevisibles Es omnipresente la tendencia a privilegiar la multiplicidad frente a la unidad.

El clamor permanente por el cultivo de la interdisciplinariedad es una especie de llamada a buscar caminos capaces de sacarnos del laberinto de las inumerables diversidades y de ayudar a reencontrar unidades. Nadie duda de que la unidad del arte es aparentemente precaria porque se presenta difícil de concebir y abarcar en la diversidad de las diferentes artes y más aún en la inabarcable e inevitable diversidad de sus obras. Pero estos hechos no deberían desanimarnos; en primer lugar, porque la aceptación resignada de la mera diversidad nos lleva hacia la confusión y la vacilación permanentes, y, en segundo lugar, porque nuestras experiencias racionales nos muestran que la verdad se halla en la unidad que se oculta tras las diversidades.

Cuando la interdisciplinariedad sirve únicamente para aumentar la multiplicidad todavía no ha asumido su deber y su misión. A ello contribuyen también numerosos artistas cuyo afán debería ser igualmente la creación de unidades haciéndonos ver con ellas lo verdadero, lo bueno y lo bello. La ligereza con la que demasiado a menudo se hace arte y se escriben estudios sobre el arte resulta tan arriesgada que están peligrando el arte y la cultura. Nadie debería estar interesado en que llegue ese momento.

Es precisamente una definición general del arte la que será capaz de descubrir los numerosos puntos y solapamientos comunes entre las artes y las posibilidades de comparación. Uno de los aspectos menos trabajados y, sin embargo, más fértiles en este orden de ideas me parece ser el estudio de los modos y los géneros en las diferentes artes. Y, ante todo, el conocimiento de los aspectos comunes que comparten todas las artes facilitará la comprensión y la interpretación de las obras artísticas y ayudará sin duda a encontrar y aplicar criterios más sólidos que ayuden a distinguir más objetivamente el arte de la impostura. 


\title{
RESUMEN
}

Repasando la literatura como arte, por Kurt Spang.

Hay que hacer lo que une. La agopiante multiplicación de definiciones del arte y de la literatura que va acumulando el pensamiento postmoderno vuelve urgente una reflexión sobre los aspectos y criterios comunes que poseen las artes y con ello, los criterios que permiten definir la literatura como una de las artes más allá de la diversidad histórica y fáctica que evidentemente existe. Este ensayo propone una nueva y a la vez antigua definición de las artes basada en la capacidad y obligación de las artes de hacer transparente el ser a través de los transcendentales.

Palabras claves: Cultura, arte, literatura.

\begin{abstract}
We should do what unites. The burdening multiplication of definitions of art and literature which accumulantes postmodern thinking makes urgent a reflection about the common aspects and criteria of art and thus about the criteria allowing a definition of literature as one of the arts beyond all historical and factical diversity which logically must exist. The essay proposes a new and altogether ancient definition of the arts based on their capacibility and obligation to make transparent being by means of the transcendentals.
\end{abstract}

Keywords: Culture, art, literature. 